\title{
Radiated energy from the Noto Hanto, Japan, earthquake of March 25, 2007, and its aftershock
}

\author{
Yasuo Izutani \\ Shinshu University, 4-17-1 Wakasato, Nagano, Japan \\ (Received June 20, 2007; Revised August 17, 2007; Accepted August 28, 2007; Online published February 19, 2008)
}

\begin{abstract}
The Noto Hanto earthquake of March 25, 2007, is a shallow reverse-faulting event with $M_{\mathrm{w}}=6.7$. We analyze transverse component accelerograms of the main shock and an aftershock $\left(M_{\mathrm{w}}=3.6\right)$ recorded at 10 strong motion observation stations. The hypocenter of the aftershock is located very close to that of the main shock and the epicentral distances of the stations are between 15 and $65 \mathrm{~km}$. We calculate spectral ratio between records of the main shock and the aftershock in order to obtain source spectral ratio by empirically removing the effects of wave propagation path and surface layers at the stations. Thus obtained source spectral ratio is inconsistent with that expected for the self-similar omega-square source model assuming constant stress drop. Fitting omegasquare source spectral ratio with variable corner frequency to the observed spectral ratio, the radiated energy and the corner frequency for the main shock and the aftershock are estimated. The radiated energy is $6.8 \times 10^{14} \mathrm{~J}$ for the main shock and $6.7 \times 10^{9} \mathrm{~J}$ for the aftershock. The energy-to-moment ratios for the main shock and the aftershock are $5.0 \times 10^{-5}$ and $2.1 \times 10^{-5}$. This scale-dependence of the energy-to-moment ratio is similar to that obtained previously for shallow strike-slip earthquakes and reverse-faulting earthquakes in Japan. The relationship between the seismic moment, $M_{0}$, and the corner frequency, $f_{0}$, is $M_{0} \propto f_{0}^{-3.3 \pm 0.2}$.
\end{abstract}

Key words: 2007 Noto Hanto earthquake, radiated energy, corner frequency, similarity of earthquake source.

\section{Introduction}

Scaling of earthquake source parameters with size, tectonic environments, and other factors that may influence the rupture process is a very important issue. One of the approaches to this issue is to investigate the scale-dependence of seismic energy-to-moment ratio, $\tilde{e}=E_{\mathrm{R}} / M_{0}$, for earthquakes of various size which occurred in various tectonic regions. The scale-dependence of $\tilde{e}$ would provide an important clue to the difference in dynamic source process of large and small earthquakes. The regional variations in the scale-dependence may reflect the difference in seismogenic process in various tectonic environments. Also, the scaledependence plays an important role in the assumption of a scaling parameter to make a correction for the deviation from the similarity of earthquake source when we predict strong ground motion due to future large earthquakes by the empirical Green's function method (e.g., Irikura, 1986; Yokoi and Irikura, 1991; Irikura and Kamae, 1994; Izutani, 2007).

According to Ide and Beroza (2001), Ide (2003) and Yamada et al. (2005), ẽ is almost constant between $10^{-6}$ and $10^{-4}$ over a wide moment range from micro earthquakes in a gold mine $\left(M_{0} \sim 10^{4} \mathrm{~N} \mathrm{~m}\right)$ to great earthquakes in the subduction zone $\left(M_{0} \sim 10^{21} \mathrm{~N} \mathrm{~m}\right)$. On the other hand, Kanamori et al. (1993), Abercrombie (1995), Mayeda and Walter (1996), Mori et al. (2003), and Mayeda et al. (2005) pointed out that $\tilde{e}$ is scale-dependent for earthquakes in southern California.

Izutani and Kanamori (2001) analyzed four shallow strike-slip events with $M_{\mathrm{w}}=6.0 \sim 6.6$ and their aftershocks which occurred in the south-western part of Japan. They found that $\tilde{e}$ increases with the earthquake size. Izutani (2005) analyzed the Mid Niigata earthquake of October 23,2004 , a shallow reverse-faulting event in the central part of Japan with $M_{\mathrm{w}}=6.6$, and its four aftershocks. The result shows almost the same scale-dependence of $\tilde{e}$ as that found for the strike-slip events by Izutani and Kanamori (2001). The scale-dependence of $\tilde{e}$ for these earthquakes in Japan is similar to that in southern California.

The Noto Hanto earthquake of March 25, 2007, with $M_{\mathrm{w}}=6.7$ occurred in the central part of Japan (see Fig. 1). This earthquake is a shallow reverse-faulting event. Reverse-faulting is one of the two typical focal mechanisms (strike-slip-faulting and reverse-faulting) for shallow earthquakes in Japan. It was followed by aftershocks and the ground accelerations for these earthquakes are recorded at the stations of strong motion observation networks (KNET and KiK-net) operated by National Research Institute for Earth Science and Disaster Prevention, Japan (NIED). Therefore, there are a large quantity of high quality close-in records for these earthquakes. We analyze the strong motion records of the main shock and an aftershock whose hypocenter is very close to that of the main shock to investigate the scale-dependence of $\tilde{e}$ for these events. 

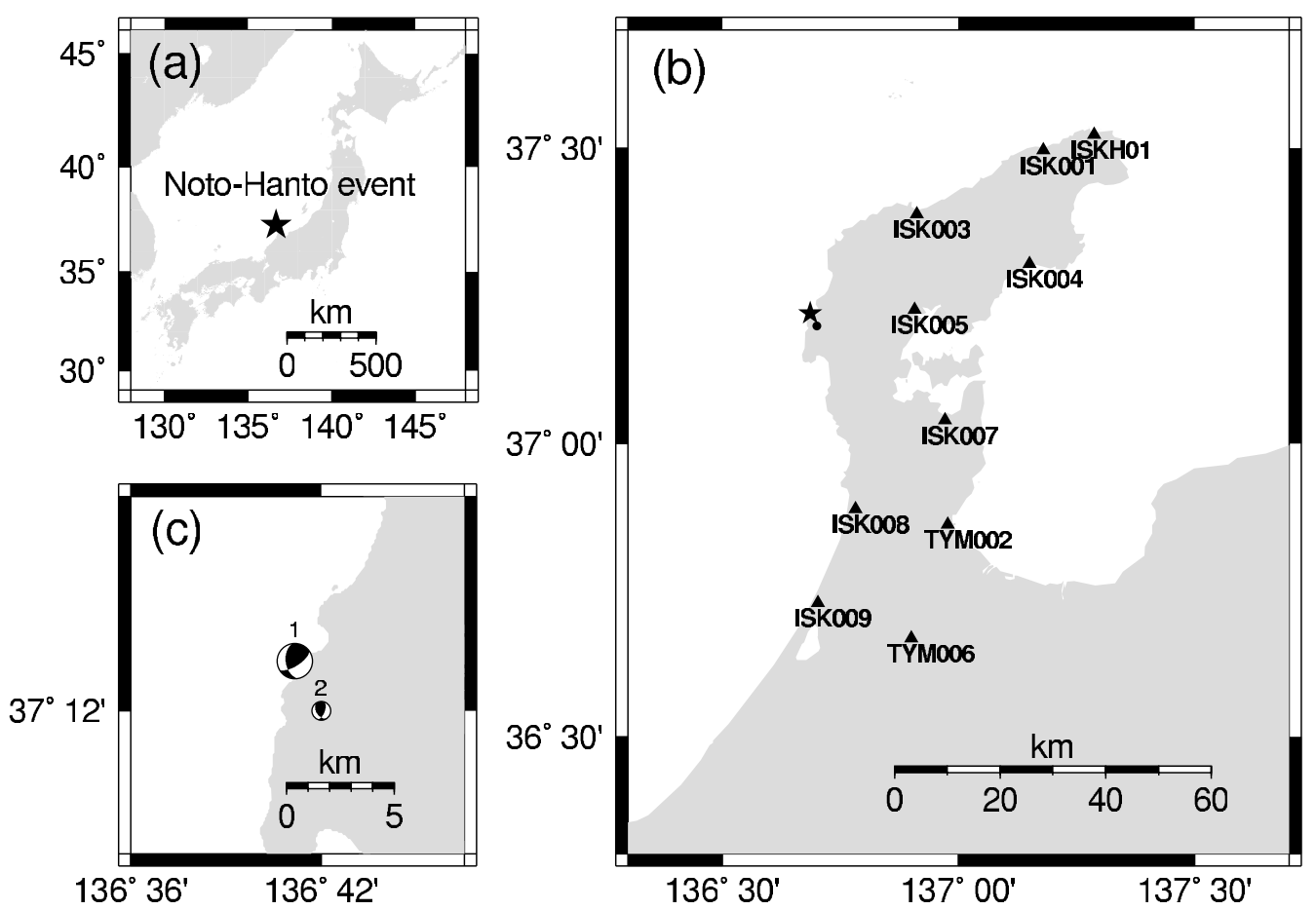

Fig. 1. (a) Location of epicenter of the 2007 Noto Hanto earthquake. (b) Locations of epicenters of the main shock (star) and the aftershock (solid circle), and the K-NET and KiK-net stations (triangles). (c) Focal mechanism solutions for the main shock (Event 1) and the aftershock (Event 2).

Table 1. List of earthquakes.

\begin{tabular}{ccccccc}
\hline Event & $\begin{array}{c}\text { Date } \\
(\mathrm{y} \mathrm{m} \mathrm{d} \mathrm{h} \mathrm{m})\end{array}$ & $\begin{array}{c}\text { Latitude } \\
(\mathrm{N})\end{array}$ & $\begin{array}{c}\text { Longitude } \\
(\mathrm{E})\end{array}$ & $\begin{array}{c}\text { Depth } \\
(\mathrm{km})\end{array}$ & $M_{\mathrm{w}}$ & $\begin{array}{c}M_{0} \\
(\mathrm{~N} \mathrm{~m})\end{array}$ \\
\hline 1 & 200703250941 & 37.221 & 136.686 & 11 & 6.7 & $1.36 \times 10^{19}$ \\
2 & 200703280057 & 37.200 & 136.700 & 10 & 3.6 & $3.18 \times 10^{14}$ \\
\hline
\end{tabular}

Origin time (Japan Standard Time. GMT+9h) and hypocenter location: after Japan Meteorological Agency (JMA). $M_{\mathrm{w}}$ and $M_{0}$ : after National Research Institute for Earthquake Science and Disaster Prevention, Japan (NIED).

\section{Data and Method of Analysis}

Table 1 lists the main shock (Event 1) of the 2007 Noto Hanto earthquake and its aftershock (Event 2) analyzed in this study. The origin time and the hypocenter location are determined by Japan Meteorological Agency (JMA). The seismic moment and the moment magnitude are determined by F-net, the broad-band seismometer network operated by NIED. This aftershock has been chosen because the hypocenter is located within $5 \mathrm{~km}$ from that of the main shock and the focal mechanism solution and the seismic moment have been determined by F-net. There are strong motion records of this aftershock at $10 \mathrm{~K}-\mathrm{NET}$ and KiKnet stations shown in Fig. 1(b). According to the F-net catalog within 2 months after the main shock, there are five more aftershocks whose hypocenters are located within $5 \mathrm{~km}$ from that of the main shock. However, since four of them have no strong motion record and one of them has strong motion records at only 4 stations, they are not analyzed in the present study.

Figure 1(a) shows the location of the epicenter of the main shock. Figure 1(b) shows the locations of the epicenters of the main shock (star) and the aftershock (solid circle), and the strong motion observation stations (triangles) whose accelerograms are analyzed in the present study. The stations are located between $15 \mathrm{~km}$ and $65 \mathrm{~km}$ from the epi- center of the main shock. Figure 1(c) shows the focal mechanism solutions for the two events by F-net.

The essential part of the method of analysis used here is the same as that used in Izutani (2005). We analyze the transverse component records obtained by rotating the two horizontal components. We window 60-sec long records from the first $P$-wave arrival. Since $S$-wave is dominant on the transverse component, the Fourier spectra obtained from the records are regarded as $S$-wave spectra of transverse component ground acceleration. We take the spectral ratio between the Fourier spectra of the main shock and the aftershock to obtain the source spectral ratio by removing the effect of the radiation pattern, the path effect and the site effect.

The spectral ratio thus obtained for the pair of events varies among the stations. This variation is due to some factors which are not perfectly removed by the above procedure, such as the effects of small differences in the focal mechanism solutions and the hypocenters. Assuming that the influence of these factors can be removed by taking the average of logarithmic amplitudes of the spectral ratios at the stations, we regard the average spectral ratio as the source spectral ratio. Unfortunately, the stations are located only in the limited azimuthal range (between $45^{\circ}$ and $180^{\circ}$ ) surrounding the epicenters as shown in Fig. 1(b). The influ- 
ence of the distribution of stations on the estimation of the radiated energy and the corner frequency will be examined in Section 4.

Theoretical source spectrum, $\dot{M}(f)$, is assumed to have $\omega^{-2}$ fall-off above the corner frequency, $f_{0}$, (Aki, 1967; Brune, 1970) as

$$
\dot{M}(f)=\frac{M_{0}}{1+\left(f / f_{0}\right)^{2}} .
$$

According to the result by Izutani and Kanamori (2001), the assumption of $\omega^{-2}$ fall-off is reasonable for events in the magnitude range of the present study. The averaged spectral ratio of the records is compared with the ratio of the theoretical source spectra,

$$
\frac{\dot{M}_{1}(f)}{\dot{M}_{2}(f)}=\frac{M_{01}\left[1+\left(f / f_{02}\right)^{2}\right]}{M_{02}\left[1+\left(f / f_{01}\right)^{2}\right]},
$$

where the suffixes 1 and 2 stand for the main shock and the aftershock. The values of $M_{0}$ by F-net are adopted because the ground acceleration data analyzed in the present study do not have enough signal-to-noise ratio in the low frequency range to determine $M_{0}$ with sufficient accuracy.

The corner frequencies, $f_{01}$ and $f_{02}$, are estimated by minimizing the sum of squared residuals between the logarithmic amplitude of the observed spectral ratio and that of the theoretical source spectral ratio. This method for estimating the corner frequency is the same as that used by Hough and Kanamori (2001). Then the radiated seismic energy, $E_{\mathrm{R}}$, is evaluated by integrating the theoretical source spectrum with the corner frequency obtained above as

$$
E_{\mathrm{R}}=\frac{4 \pi}{5 \rho \beta^{5}} \int_{0}^{\infty}|f \dot{M}(f)|^{2} \mathrm{~d} f,
$$

where $\rho$ is the density and $\beta$ is the $S$-wave velocity in the source region, and they are assumed to be the same values ( $\rho=2.7 \mathrm{~g} / \mathrm{cm}^{3}$ and $\beta=3.3 \mathrm{~km} / \mathrm{sec}$ ) used by Izutani and Kanamori (2001). The contribution of $P$-wave to the radiated energy is assumed to be about $7 \%$ of the total radiated energy (Mayeda et al., 2005) and $E_{\mathrm{R}}$ obtained by Eq. (3) is multiplied by 1.07 .

\section{Radiated Energy and Corner Frequency}

The solid curve in Fig. 2 shows the spectral ratio of the records. The theoretical source spectral ratio expressed by Eq. (2) approaches $M_{01} / M_{02}$ in the low-frequency range and $M_{01} f_{01}^{2} / M_{02} f_{02}^{2}$ in the high-frequency range. Therefore, the corner frequencies are constrained not only by the frequency at the corners of the spectral ratio but also the amplitude of the spectral ratio in the high-frequency range. If we assume the self-similar omega-square source model for constant stress drop (Aki, 1967),

$$
M_{0} \propto f_{0}^{-3}
$$

is expected. Therefore, the high-frequency source spectral ratio, $M_{01} f_{01}^{2} / M_{02} f_{02}^{2}$, for the self-similar omega-square source model becomes $\left(M_{01} / M_{02}\right)^{1 / 3}$. The upper and lower dotted lines in Fig. 2 show $M_{01} / M_{02}$ and $\left(M_{01} / M_{02}\right)^{1 / 3}$, respectively. The thin dashed curves show spectral ratios expected for the self-similar omega-square source model with five tentative pairs of $f_{01}$ and $f_{02}$.

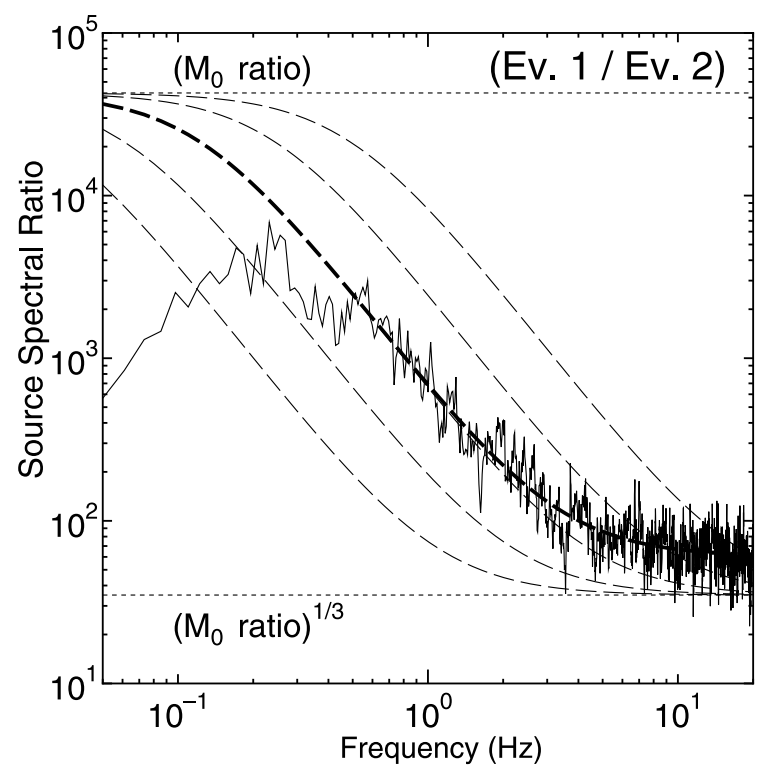

Fig. 2. Spectral ratio between the main shock (Event 1) and the aftershock (Event 2). Solid curve: observed spectral ratio, upper dotted line: ratio of seismic moment between the events, lower dotted line: the one third power of the seismic moment ratio, thin dashed curves: spectral ratios expected for the self-similar omega-square source model with five tentative pairs of corner frequencies, thick dashed curve: the best fit theoretical source spectral ratio expressed by Eq. (2).

Table 2. Radiated energy and corner frequency.

\begin{tabular}{cccc}
\hline Event & $\begin{array}{c}E_{\mathrm{R}} \\
(\mathrm{J})\end{array}$ & $\begin{array}{c}\tilde{e} \\
\left(\times 10^{-5}\right)\end{array}$ & $\begin{array}{c}f_{0} \\
(\mathrm{~Hz})\end{array}$ \\
\hline 1 & $6.8 \times 10^{14}$ & 5.0 & 0.12 \\
2 & $6.7 \times 10^{9}$ & 2.1 & 3.3 \\
\hline
\end{tabular}

The observed spectral ratio for the event pair does not approach $M_{01} / M_{02}$ in the low frequency range but decrease with decreasing frequency. Since the signal-to-noise ratio for the small event at long periods is poor, the observed spectral ratio at frequencies lower than $0.5 \mathrm{~Hz}$ is not reliable. The spectral ratio falls in the low frequency range because of the increased noise for the small event. We used the spectral ratio over the frequency range from $0.5 \mathrm{~Hz}$ to $10 \mathrm{~Hz}$ to estimate $f_{01}$ and $f_{02}$ by using a grid search method.

The spectral ratio of the records is larger than $\left(M_{01} / M_{02}\right)^{1 / 3}$ in the high-frequency range, which suggests that $f_{01}$ is too large or $f_{02}$ is too small in comparison with the expectation from the self-similar omega-square source model. The thick dashed curve indicates the best fit source spectral ratio calculated by Eq. (2). The theoretical source spectral ratio fits the observation fairly well. Optimal values for $E_{\mathrm{R}}$ and $f_{0}$ are estimated and listed in Table 2.

Figure 3 shows the seismic energy-to-moment ratio, $\tilde{e}$, plotted against $M_{\mathrm{w}}$. The results for shallow strike-slip earthquakes in the south-western part of Japan (Izutani and Kanamori, 2001) and for shallow reverse-faulting earthquakes in the central part of Japan (Izutani, 2005) are also plotted in the figure. The plots of $\tilde{e}$ for the Noto Hanto events are located near the upper bounds of the plots in Fig. 3 and $\tilde{e}$ for the main shock is larger than that of the aftershock. This scale-dependence of $\tilde{e}$ obtained for the Noto 


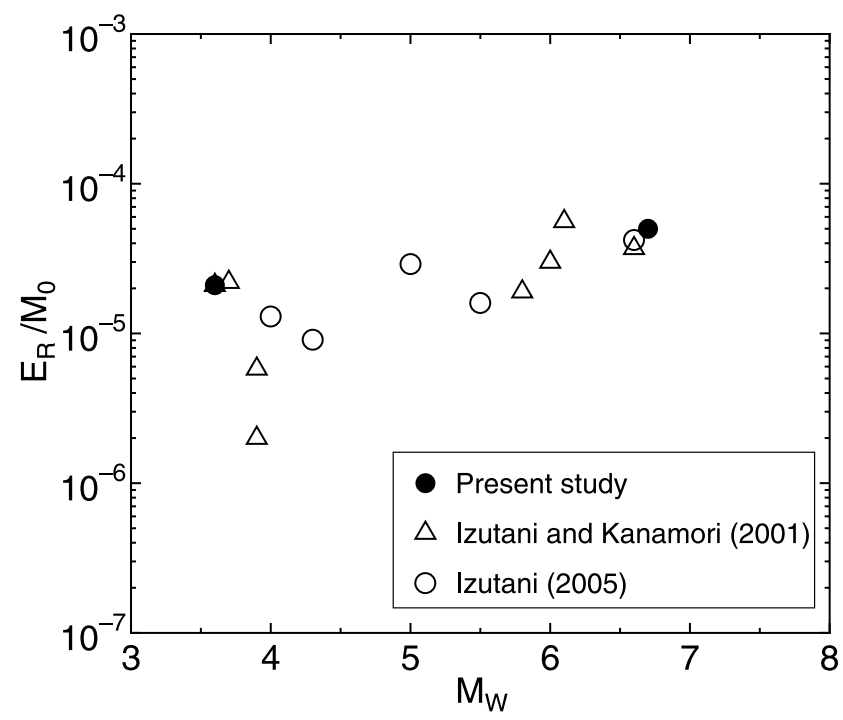

Fig. 3. Seismic energy-to-moment ratio as a function of $M_{\mathrm{w}}$. Izutani and Kanamori (2001) is the result for shallow strike-slip earthquakes in the south-western part of Japan and Izutani (2005) is the result for shallow reverse-faulting earthquakes in the central part of Japan.

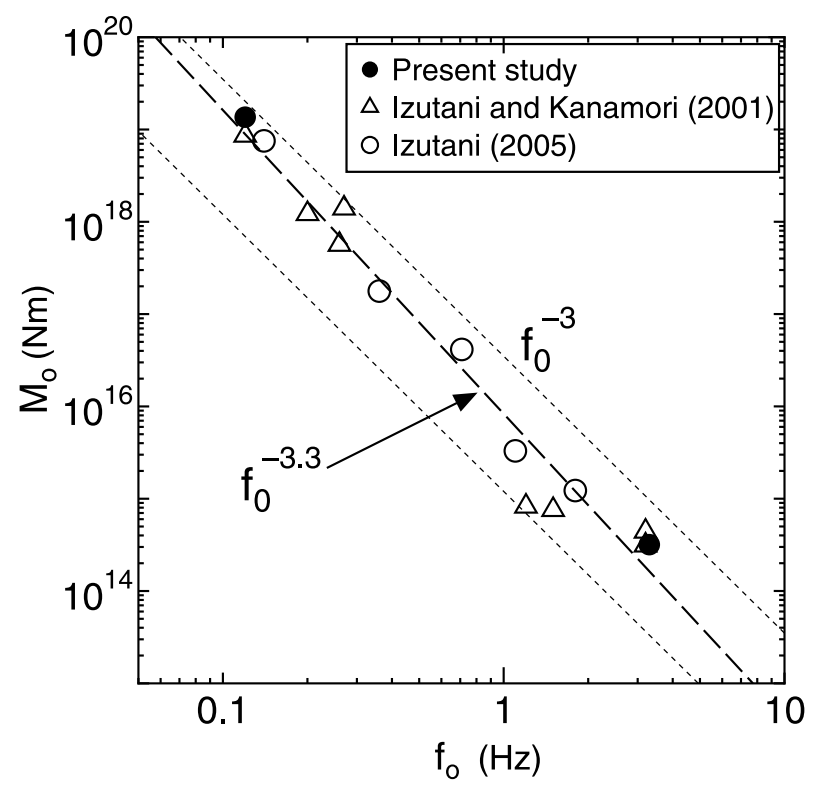

Fig. 4. Relationship between seismic moment, $M_{0}$, and corner frequency, $f_{0}$. The dotted lines indicate $M_{0} \propto f_{0}^{-3}$ expected for the self-similar omega-square source model and the dashed line indicates the regression result, $M_{0} \propto f_{0}^{-3.3}$.

Hanto events is consistent with that found for the shallow earthquakes in Japan by the previous studies.

Figure 4 shows the relationship between $M_{0}$ and $f_{0}$. The present result, the results by Izutani and Kanamori (2001) and Izutani (2005) are plotted together in the figure. The three results are consistent with each other in spite of the difference in the focal mechanism. A linear regression analysis is carried out between $\log M_{0}$ and $\log f_{0}$ for the all events in the figure and the following relationship,

$$
M_{0} \propto f_{0}^{-3.3 \pm 0.2}
$$

is obtained as shown by the dashed line in the figure. This result of regression analysis is the same as that obtained by

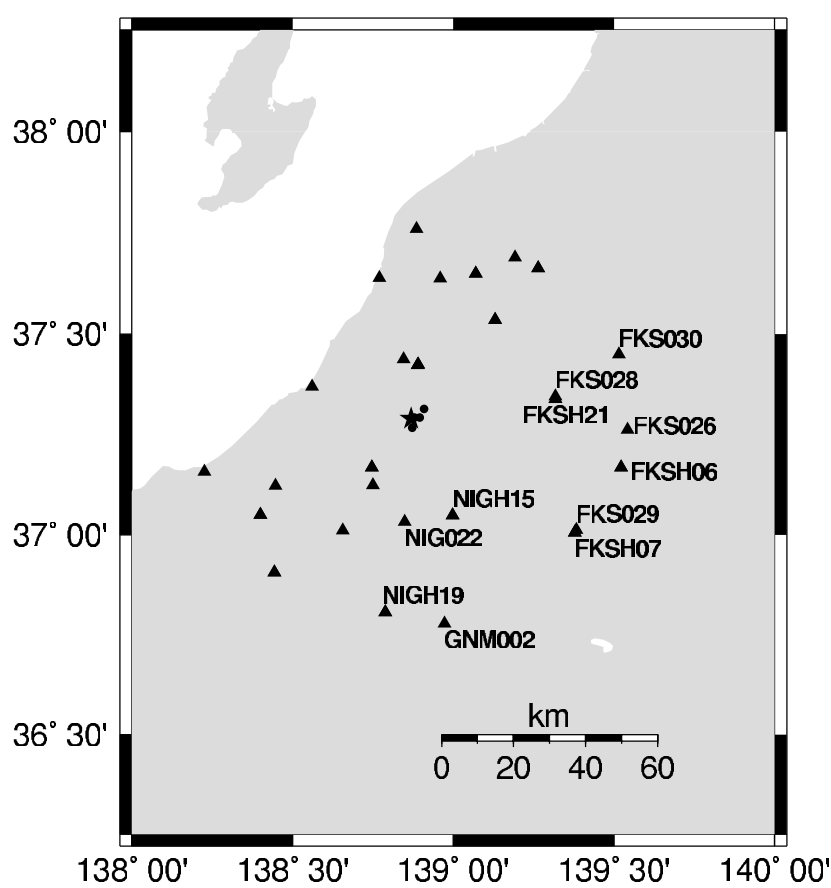

Fig. 5. Locations of epicenters of the 2004 Mid Niigata earthquake (star) and its four aftershocks (solid circles) analyzed by Izutani (2005). The triangles are the K-NET and KiK-net stations used by Izutani (2005). The stations with the station codes are used in the present study to examine the influence of the distribution of stations on the estimates of $E_{\mathrm{R}}$ and $f_{0}$.

Izutani (2005) for the earthquakes analyzed by Izutani and Kanamori (2001) and the mid Niigata earthquake and its aftershocks.

\section{Influence of Station Distribution}

The distribution of stations is an important factor to obtain reliable estimates of $E_{\mathrm{R}}$ and $f_{0}$ by the spectral ratio method used in the present study. Using stations which surround the epicenters of paired events, we would be able to average out the effects of the small differences in the focal mechanisms and the hypocenters between the paired events. Unfortunately, the distribution of the stations used in the present study is not optimal as shown in Fig. 1(b). All of the stations are located in the azimuthal range between $45^{\circ}$ and $180^{\circ}$ around the epicenter of the main shock. We examine the influence of the insufficient azimuthal coverage of the stations on the estimation of $E_{\mathrm{R}}$ and $f_{0}$.

Figure 5 shows the epicenters of the 2004 Mid Niigata earthquake and its four aftershocks analyzed by Izutani (2005). Since the azimuthal coverage of the stations around the Mid Niigata events is optimal for the spectral ratio analysis, $E_{\mathrm{R}}$ and $f_{0}$ estimated by Izutani (2005) would have enough accuracy. Here, we try to estimate $E_{\mathrm{R}}$ and $f_{0}$ by using only the stations with the station codes in Fig. 5, which are located in the azimuthal range between $55^{\circ}$ and $190^{\circ}$. The location of the aftershocks relative to the main shock and the distribution of the stations with the station codes are very similar to the case of the Noto Hanto events in Fig. 1(b).

$\tilde{e}$ and $f_{0}$ estimated here are compared with those by Izutani (2005) in Figs. 6 and 7. Although $\tilde{e}$ and $f_{0}$ are a lit- 


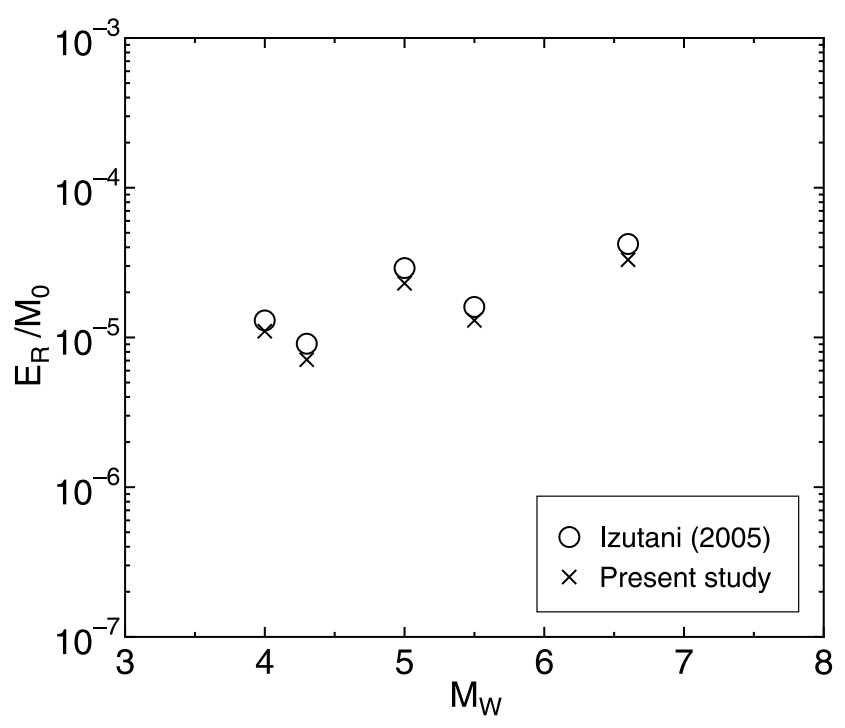

Fig. 6. Seismic energy-to-moment ratio as a function of $M_{\mathrm{w}}$ for the 2004 Mid Niigata earthquake and its four aftershocks. Open circles are the results by Izutani (2005). Crosses are the results of the present study by using only the stations with the station codes in Fig. 5 .

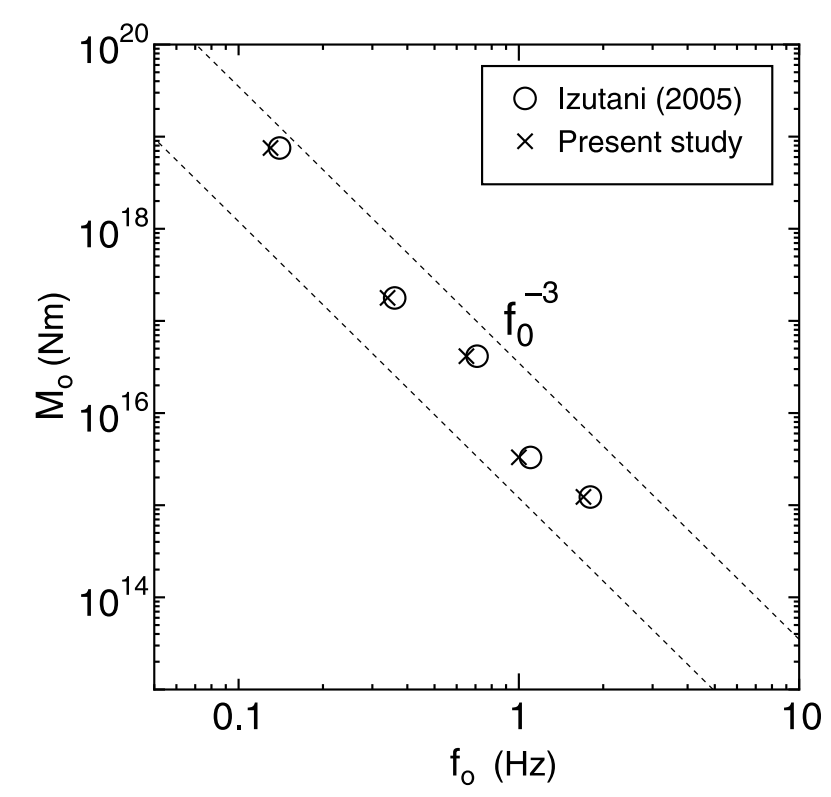

Fig. 7. Relationship between seismic moment, $M_{0}$, and corner frequency, $f_{0}$, for the 2004 Mid Niigata earthquake and its four aftershocks. Open circles are the results by Izutani (2005). Crosses are the results of the present study by using only the stations with the station codes in Fig. 5. The dotted lines indicate $M_{0} \propto f_{0}^{-3}$ expected for the self-similar omega-square source model.

tle smaller than those by Izutani (2005), the essential part of the result does not change. The scale-dependence of $\tilde{e}$ still appears in Fig. 6 and the relationship between $M_{0}$ and $f_{0}$ still shows a steeper trend than $M_{0} \propto f_{0}^{-3}$ in Fig. 7. The decrease in $\tilde{e}$ and $f_{0}$ would be qualitatively understood as follows: The spectral ratio between the main shock and each of the aftershocks is reduced because the stations with the station codes in Fig. 5 are located closer to the aftershocks than the main shock. Then, $f_{01}$ and $f_{02}$ for the best fit theoretical spectral ratio decrease as easily deduced from Fig. 2, and $E_{\mathrm{R}}$ and $\tilde{e}$ become smaller than those by Izutani
(2005).

Although the influence of station distribution involves in various effects that are different from event to event such as the radiation pattern, coupling of seismic waves with the heterogeneity through the propagation paths etc., the above examination is helpful in estimating the reliability of the present result. The values in Table 2 may be a little smaller than real values of $E_{\mathrm{R}}, \tilde{e}$ and $f_{0}$ for the Noto Hanto events. However, the above examination suggests that the scaledependence of $\tilde{e}$ in Fig. 3 and the relationship between $M_{0}$ and $f_{0}$ in Fig. 4 are not severely affected by the insufficient azimuthal coverage of the stations used in the present study.

\section{Discussion and Conclusion}

The scale-dependence of seismic energy-to-moment ratio, $\tilde{e}=E_{\mathrm{R}} / M_{0}$, for the 2007 Noto Hanto earthquake and its aftershock is similar to those obtained previously by Izutani and Kanamori (2001) and Izutani (2005) for shallow strike-slip earthquakes and reverse-faulting earthquakes in Japan. Large earthquakes radiate more short-period seismic energy per unit seismic moment than small ones, which suggests a deviation from the similarity law of earthquake sources. The scale-dependence of $\tilde{e}$ suggests the difference in physical properties between large and small earthquakes in Japan.

Collecting $\tilde{e}$ for earthquakes in various tectonic environments (e.g., Ide and Beroza, 2001) apparently shows constant $\tilde{e}$ with very large scatter. However, $\tilde{e}$ for a suite of events in a specific tectonic region definitely shows scaledependence as obtained in the present study and many previous studies (e.g., Kanamori et al., 1993; Abercrombie, 1995; Mayeda and Walter, 1996; Izutani and Kanamori, 2001; Mori et al., 2003; Mayeda et al., 2005; Izutani, 2005).

Based on physical consideration on the earthquake source, Kanamori and Rivera (2004) presented a relationship between $M_{0}$ and $f_{0}$ as

$$
M_{0} \propto\left(\Delta \sigma_{s} V^{3}\right) f_{0}^{-3}
$$

where $\Delta \sigma_{s}$ is the stress drop and $V$ is the rupture velocity. Also, about the minimum value of $\tilde{e}$, they obtained an expression,

$$
\tilde{e}_{\min } \propto \Delta \sigma_{s} V^{3}
$$

The self-similar omega-square source model assuming constant $\Delta \sigma_{s}$ and constant $V$ expects constant $\tilde{e}_{\min }$ and $M_{0} \propto$ $f_{0}^{3}$. The scale-dependence of $\tilde{e}$ and the relationship, $M_{0} \propto$ $f_{0}^{-(3+\epsilon)}$, where $\epsilon=0.3$ in the present study, suggest a break in the assumptions. Moreover, Kanamori and Rivera (2004) suggested that even if $\tilde{e}$ is scale independent and $M_{0} \propto f_{0}^{-3}$, $\Delta \sigma_{s}$ is not necessarily scale independent. To advance the study on the physical meaning of the scale dependent $\Delta \sigma_{s}$ and $V$, it is necessary to evaluate $\Delta \sigma_{s}$ and $V$ independently.

Acknowledgments. Accelerogams from K-NET and KiK-net stations operated by National Research Institute for Earth Science and Disaster Prevention, Japan, are used in this study. Comments from F. Tajima and an anonymous reviewer were very helpful in the revision of the manuscript. 


\section{References}

Abercrombie, R. E., Earthquake source scaling relationship from -1 to 5 using seismograms recorded at $2.5-\mathrm{km}$ depth, J. Geophys. Res., 100, 24015-24036, 1995.

Aki, K., Scaling law of seismic spectrum, J. Geophys. Res., 72, 1217-1231, 1967.

Brune, J. N., Tectonic stress and spectra of seismic shear waves from earthquakes, J. Geophys. Res., 75, 4997-5009, 1970.

Hough, S. E. and H. Kanamori, Source properties of earthquakes near the Salton Sea triggered by the 10/16/1999 M7.1 Hector Mine earthquake, Bull. Seismol. Soc. Am., 91, 456-467, 2001.

Ide, S., Apparent break in earthquake scaling due to path and site effects on deep borehole recordings, J. Geophys. Res., 108(B5), 2271, doi:10. 1029/2001JB001617, 2003.

Ide, S. and G. C. Beroza, Does apparent stress vary with earthquake size?, Geophys. Res. Lett., 28, 3349-3352, 2001.

Irikura, K., Prediction of strong acceleration motion using empirical Green's function, Proc. 7th Japan Earthq. Eng. Symp., 151-156, 1986.

Irikura, K. and K. Kamae, Estimation of strong ground motion in broadfrequency band based on a seismic source scaling model and an empirical Green's function technique, ANNALI DI GEOFISICA, 37, 25-47, 1994.

Izutani, Y., Radiated energy from the mid Niigata, Japan, earthquake of October 23, 2004, and its aftershocks, Geophys. Res. Lett., 32, L21313, doi:10.1029/2005GL024116, 2005.

Izutani, Y., Scaling of short-period source spectrum for earthquakes in mid Niigata, Japan, Earth Planets Space, 59, 301-305, 2007.

Izutani, Y. and H. Kanamori, Scale dependence of seismic energy-to- moment ratio for strike-slip earthquakes in Japan, Geophys. Res. Lett., 28, 4007-4010, 2001.

Kanamori, H. and L. Rivera, Static and dynamic scaling relations for earthquakes and their implications for rupture speed and stress drop, Bull. Seismol. Soc. Am., 94, 314-319, 2004.

Kanamori, H., E. Hauksson, L. K. Hutton, and L. M. Jones, Determination of earthquake energy release and ML using TERRAscope, Bull. Seismol. Soc. Am., 83, 330-346, 1993.

Mayeda, K. and W. R. Walter, Moment, energy, stress drop, and source spectra of western United States earthquakes from regional coda envelopes, J. Geophys. Res., 101, 11,195-11,208, 1996.

Mayeda, K., R. Gök, W. R. Walter, and A. Hofstetter, Evidence for non-constant energy/moment scaling from coda-derived source spectra, Geophys. Res. Lett., 32, L10306, doi:10.1029/2005GL022405, 2005.

Mori, J., R. E. Abercrombie, and H. Kanamori, Stress drops and radiated energy of aftershocks of the 1994 Northridge, California, earthquake, $J$. Geophys. Res., 108(B11), 2545, doi:10.1029/2001JB000474, 2003.

Yamada, T., J. J. Mori, S. Ide, H. Kawakata, Y. Iio, and H. Ogasawara, Radiation efficiency and apparent stress of small earthquakes in a South African gold mine, J. Geophys. Res., 110(B01), 305, doi:10.1029/2004JB003221, 2005.

Yokoi T. and K. Irikura, Empirical Green's function technique based on the scaling law of source spectra, Zisin, Ser. 2, 44, 109-122, 1991 (in Japanese).

Y. Izutani (e-mail: tdp0000@gipwc.shinshu-u.ac.jp) 